\title{
Estimation of biomarkers in asphyxiated full term neonates with special reference to serum lactate dehydrogenase, aspartate transaminase and alanine transaminase
}

\author{
C H Rajeesha ${ }^{1}$, *K S Sahana ${ }^{1}$, R M S Prakash ${ }^{1}$ \\ Sri Lanka Journal of Child Health, 2020; 49(2): 162-169
}

Background: A variety of parameters are used to identify perinatal asphyxia but they should be easily obtainable, fast and cost-effective.

Objectives: To assess the levels of serum lactate dehydrogenase (LDH), aspartate transaminase (AST) and alanine transaminase (ALT) among asphyxiated term neonates at birth (in cord blood), $0-4$ hours and 18 to 24 hours after birth, to compare their levels in 3 grades of asphyxia, to correlate the values with the severity of asphyxia and to ascertain the best time interval for their estimation.

Method: A hospital-based longitudinal study was done on 30 full term asphyxiated neonates. Plasma LDH, AST and ALT were tested in cord blood at birth and the neonates' venous blood within 4 hours and between 18-24 hours. Babies were monitored clinically for evidence of hypoxic ischaemic encephalopathy (HIE) with laboratory parameters. Neonates were followed up till discharge.

Results: Serum LDH value showed a rising trend at all time points in which maximum values were observed between 18 and 24 hours of life (mean value $2153.10 \pm 1992.15 \mathrm{U} / \mathrm{L}$ ). On correlation of LDH, AST and ALT between the stages of HIE at different time points, strong correlation coefficients were observed between serum LDH done within 4 hours of birth and serum LDH done between 18 to 24 hours with higher stages of HIE.

Conclusions: The best time period for predicting severity of asphyxia in terms of serum LDH and AST was between 18 to 24 hours whereas a high cord LDH value would suggest increased severity

\footnotetext{
${ }^{1}$ Yenepoya University, Mangalore, India

*Correspondence: dr_sahana2003@yahoo.co.in iD orcid.org/ 0000-0002-7834-0289
}

(Received on 13 August 2019: Accepted after revision on 20 September 2019)

The authors declare that there are no conflicts of interest

Personal funding was used for the project.

Open Access Article published under the Creative

Commons Attribution CC-BY (cC) (i) License of asphyxia. ALT levels did not show any significance in any point of time within 24 hours.

DOI: http://dx.doi.org/10.4038/sljch.v49i2.8964

(Key words: Biomarkers, birth asphyxia, AST, ALT)

\section{Introduction}

Globally, birth asphyxia accounts for $17 \%$ of newborn deaths and severe neurological sequelae occur in $25 \%$ of surviving infants ${ }^{1}$. Birth asphyxia continues to be a major causes of mortality and morbidity in neonates despite advances in neonatal medicine ${ }^{2}$. National neonatal perinatal database shows that in India birth asphyxia contributes to almost $23 \%$ of neonatal mortality ${ }^{3}$. Though multiorgan involvement, including kidneys, liver and lungs, is seen in neonates with birth asphyxia, involvement of the central nervous system is more detrimental ${ }^{2}$. Though the clinical manifestations of hypoxic ischaemic encephalopathy (HIE) are well defined (Sarnat and Sarnat staging), complete establishment of clinical signs may take a long time. However, early recognition of HIE, including mild cerebral injury, is critical for optimum neuroprotective management.

Parameters used to identify birth asphyxia include electronic fetal monitoring, low Apgar score, cord blood $\mathrm{pH}$ value, electroencephalogram (EEG) and magnetic resonance imaging (MRI) studies, but even when combining clinical signs and these techniques, early identification of newborns with the poor outcome can still be challenging. In this context, the use of a biomarker of inflammation or oxidative stress that will increase within the initial hours of life in these newborns may help in early diagnosis of HIE and for initiating neuroprotection. Biomarkers should be easily obtainable, fast, cost effective and able to be used in the majority of labour rooms and hospitals.

Biomarkers studied to date include cytokines (IL-6, IL-b, TNF-alpha), creatinine kinase, cardiac troponins, neuron specific enolase, protein S 100, adrenomedullin, nitrotyrosine-nitrated albumin, activin A and matrix metalloproteinases ${ }^{4}$ but for most, facilities to measure their levels are not available in all centres and may not be cost effective. Through a series of protective reflexes, 
the body tries to protect vital organs (brain, heart) by diverting blood from less vital organs like kidney, intestines and liver. Because of the high metabolic demand of the liver, it is prone to ischaemic damage leading to elevation of hepatic enzymes (AST, ALT and LDH) which is usually transient and noted between 24 to 72 hours. Of these 3, LDH, being intracellular, may readily increase whenever there is hypoxic ischaemic tissue damage and it is present in all tissues. LDH can be an ideal biomarker in birth asphyxia reflecting the severity of the cellular damage ${ }^{5}$. We wanted to study these enzymes in the initial 24 hours, including cord blood, for early identification of birth asphyxia.

\section{Objectives}

- To assess levels of serum LDH, AST and ALT among asphyxiated term neonates at $0-4$ hours and 18 to 24 hours after birth.

- To compare serum LDH, AST and ALT values in 3 grades of asphyxia and to correlate the values with the severity of asphyxia and

- To ascertain the best time interval since birth to assess serum LDH, AST and ALT as biological markers for early identification of asphyxiated newborns

\section{Method}

This was a hospital based longitudinal study on 30 full term consecutive born term neonates with birth asphyxia at a tertiary care hospital from January 2016 to July 2017, a period of 18 months. Term babies with Apgar scores less than 7 at 5 minutes or evidence of fetal distress or more than 1 minute of resuscitation with positive-pressure ventilation (PPV) and oxygen in the delivery room or $\mathrm{pH}<7.2$ or base excess $(\mathrm{BE})>-12$ during the first hour of life were included in the study. Babies with congenital infections, haemolytic conditions and primary hepatobiliary disease were excluded from study. The data were collected after ethical clearance was obtained from the ethics committee of the Yenepoya University, Mangalore, India, and after taking consent from the parents.

A detailed maternal history, with demographic profile and the records of continuous electronic fetal monitoring, birth events and related risk factors were noted down. Apgar score at 5 minutes was taken into consideration. Gender, gestational age and weight of the babies were recorded. Blood was collected for plasma LDH, AST and ALT at 0, within 4 hours and between 18-24 hours. First blood sample was taken immediately after birth from cord blood in lithium heparin tubes. During the stay in the neonatal intensive care unit (NICU), a blood sample for analysis of LDH, AST and ALT was collected together with routine biochemistry within 0-4 hours and 18-24 hours. Babies were monitored clinically for evidence of hypoxic ischaemic encephalopathy using Sarnat and Sarnat staging and also for other organ dysfunction. Simultaneously, laboratory parameters including complete blood count, renal function tests, serum electrolytes, C-reactive protein, and blood glucose were noted. Final outcome in asphyxiated babies was followed up till discharge. LDH was analysed by German Society for Clinical Chemistry (DGKC) method on $1 \mathrm{ml}$ blood. AST and ALT were analysed by using enzymatic calorimetric method and UV with PSP method respectively.

With the prevalence rate of 0.0315 , as per the previous data of our hospital, with $99 \%$ confidence interval and $92 \%$ power of the test, the sample size was calculated to be 31 .

Data were entered in MS-Excel and analysed in SPSS version 22. Descriptive statistics i.e. percentages were calculated for qualitative data and for quantitative data, mean and standard deviation were done. Independent t-test and ANOVA were applied to find the significance. $\mathrm{p}<0.05$ was considered as statistically significant.

\section{Results}

Thirty babies with birth asphyxia were included in study. Thirteen (43\%) mothers were primigravida and $12(40 \%)$ mothers were in the age group 21-23 years. Nineteen (63\%) babies were born between 39 -40 weeks of gestation whilst $07(23 \%)$ were borderline post-term. Sixteen (53\%) babies were males. Twelve (40\%) babies had birth weights from $2.6-3.0 \mathrm{~kg}$ while low birth weight $(<2.5 \mathrm{~kg})$ was observed in $04(13 \%)$ and only one baby was large for gestational age (LGA). Twelve $(40 \%)$ had nonreactive non-stress test. Risk factors noted for birth asphyxia were meconium stained liquor in 13 (43\%), prolonged labour in 08 (26.7\%), instrumental delivery in $05(16.7 \%)$, and one each had pregnancy induced hypertension, gestational diabetes mellitus, placenta praevia, cord prolapse and prolonged rupture of membranes. Twenty $(66.7 \%)$ babies were moderately asphyxiated, 06 (20\%) severely asphyxiated and 04 (13.3\%) mildly asphyxiated based on the Apgar score. Ten (33.3\%) had stage $1 \mathrm{HIE}, 11(36.7 \%)$ had stage $2 \mathrm{HIE}, 06$ $(20 \%)$ had stage 3 HIE and $03(10 \%)$ had no HIE. Six $(20 \%)$ babies with severe asphyxia expired.

Mean LDH values in cord blood, within 4 hours, and at 18-24 hours were 1464, 1767 and $2153 \mathrm{U} / \mathrm{L}$ respectively. Mean AST values in cord blood, within 4 hours, and at 18-24 hours were 83, 94 and $114 \mathrm{U} / \mathrm{L}$ respectively. Mean ALT values were 41, 43 and $47 \mathrm{U} / \mathrm{L}$ respectively. Comparison of serum LDH at different time points between the different stages of HIE is shown in Tables 1 and 2 . 
Table 1: Comparison of serum lactate dehydrogenase (LDH) at different time points between the stages of hypoxic ischaemic encephalopathy (HIE)

\begin{tabular}{|c|c|c|c|c|c|c|c|c|c|}
\hline $\begin{array}{l}\text { LDH at different } \\
\text { time points }\end{array}$ & & $\mathbf{N}$ & Mean & $\begin{array}{l}\text { Standard } \\
\text { deviation }\end{array}$ & $\begin{array}{l}\text { Standard } \\
\text { error }\end{array}$ & Min & Max & $\begin{array}{l}\text { F- } \\
\text { statistic }\end{array}$ & p-value \\
\hline \multirow{4}{*}{ Cord blood LDH } & 0 & 3 & 642.00 & 34.871 & 20.133 & 618 & 682 & \multirow[t]{4}{*}{6.553} & \multirow[t]{4}{*}{$0.002 *$} \\
\hline & 1 & 10 & 1138.70 & 664.116 & 210.012 & 542 & 2722 & & \\
\hline & 2 & 11 & 1506.09 & 704.140 & 212.306 & 736 & 3000 & & \\
\hline & 3 & 6 & 2342.33 & 509.504 & 208.004 & 1820 & 3233 & & \\
\hline \multirow{4}{*}{$\begin{array}{l}\text { LDH within } 4 \\
\text { hours }\end{array}$} & 0 & 3 & 747.33 & 63.571 & 36.703 & 702 & 820 & \multirow[t]{4}{*}{12.046} & \multirow[t]{4}{*}{$<0.001^{*}$} \\
\hline & 1 & 10 & 1187.90 & 705.942 & 223.239 & 560 & 2903 & & \\
\hline & 2 & 11 & 1689.55 & 797.680 & 240.510 & 788 & 3200 & & \\
\hline & 3 & 6 & 3385.50 & 1015.433 & 414.549 & 1870 & 4833 & & \\
\hline \multirow{4}{*}{$\begin{array}{l}\text { LDH between } 18 \\
\text { and } 24 \text { hours }\end{array}$} & 0 & 3 & 869.67 & 90.523 & 52.263 & 812 & 974 & \multirow[t]{4}{*}{10.808} & \multirow[t]{4}{*}{$<0.001^{*}$} \\
\hline & 1 & 10 & 1168.20 & 694.512 & 219.624 & 560 & 2960 & & \\
\hline & 2 & 11 & 1851.64 & 997.210 & 300.670 & 812 & 3731 & & \\
\hline & 3 & 6 & 4989.00 & 2717.940 & 1109.594 & 3041 & 10289 & & \\
\hline
\end{tabular}

0-non HIE, 1-HIE stage1, 2-HIE stage 2 and 3-HIE stage 3

One way ANOVA was used to compare LDH values at different time points between the stages of HIE. Here we observe significant differences in
LDH values when done in cord blood, within 4 hours and between 18 and 24 hours with $\mathrm{p}<0.05$.

Table 2: Multiple comparison of serum lactic dehydrogenase (LDH) at different time points with the stages of hypoxic ischaemic encephalopathy (HIE)

\begin{tabular}{|c|c|c|c|c|c|c|c|}
\hline \multirow{2}{*}{$\begin{array}{l}\text { Serum } \\
\text { LDH }\end{array}$} & \multirow{2}{*}{$\begin{array}{l}\text { (I) HIE } \\
\text { stage }\end{array}$} & \multirow{2}{*}{$\begin{array}{l}\text { (J) HIE } \\
\text { stage }\end{array}$} & \multirow{2}{*}{$\begin{array}{c}\text { Mean } \\
\text { difference } \\
(\mathbf{I}-\mathbf{J})\end{array}$} & \multirow{2}{*}{$\begin{array}{l}\text { Standard } \\
\text { error }\end{array}$} & \multirow[t]{2}{*}{ p-value } & \multicolumn{2}{|c|}{$95 \%$ confidence interval } \\
\hline & & & & & & Lower bound & Upper bound \\
\hline \multirow{6}{*}{$\begin{array}{l}\text { Cord } \\
\text { blood } \\
\text { LDH }\end{array}$} & \multirow[t]{3}{*}{0} & 1 & -496.700 & 412.876 & 0.630 & -1629.35 & 635.95 \\
\hline & & 2 & -864.091 & 408.522 & 0.1755 & -1984.80 & 256.62 \\
\hline & & 3 & $-1700.333^{*}$ & 443.500 & $0.004 *$ & -2917.00 & -483.67 \\
\hline & \multirow[t]{2}{*}{1} & 2 & -367.391 & 274.045 & 0.546 & -1119.18 & 384.40 \\
\hline & & 3 & $-1203.633 *$ & 323.886 & 0.00 & -2092.16 & -315.11 \\
\hline & 2 & 3 & -836.242 & 318.318 & 0.064 & -1709.49 & 37.01 \\
\hline \multirow{6}{*}{$\begin{array}{l}\text { LDH } \\
\text { within } \\
4 \text { hours }\end{array}$} & \multirow[t]{3}{*}{0} & 1 & -440.567 & 516.587 & 0.829 & -1857.73 & 976.60 \\
\hline & & 2 & -942.212 & 511.140 & 0.277 & -2344.43 & 460.01 \\
\hline & & 3 & -2638.167 & 554.904 & $<0.001 *$ & -4160.44 & -1115.89 \\
\hline & \multirow[t]{2}{*}{1} & 2 & -501.645 & 342.883 & 473 & -1442.28 & 438.99 \\
\hline & & 3 & $-2197.600 *$ & 405.244 & $<0.001 *$ & -3309.31 & -1084.89 \\
\hline & 2 & 3 & $-1695.955^{*}$ & 398.277 & $0.001 *$ & -2788.56 & -603.35 \\
\hline \multirow{6}{*}{$\begin{array}{l}\text { LDH } \\
\text { between } \\
18 \text { and } \\
24 \text { hours }\end{array}$} & \multirow[t]{3}{*}{0} & 1 & -298.533 & 924.101 & 0.988 & -2833.64 & 2236.57 \\
\hline & & 2 & -981.970 & 914.356 & 0.708 & -3490.34 & 1526.40 \\
\hline & & 3 & $-4119.333^{*}$ & 992.644 & $0.002 *$ & -6842.47 & -1396.19 \\
\hline & \multirow[t]{2}{*}{1} & 2 & -683.436 & 613.369 & 0.684 & -2366.10 & 99.23 \\
\hline & & 3 & $-3820.800^{*}$ & 724.925 & $<0.001 *$ & -5809.50 & -1832.10 \\
\hline & 2 & 3 & -3137.364 & 712.461 & $0.001 *$ & -5091.87 & -1182.8 \\
\hline
\end{tabular}

Tukey's post-hoc test was used for multiple comparison of serum LDH values between each time point with stages of HIE. Here we observe significant differences between non-HIE and HIE stage 3 when LDH was done in cord blood. When serum LDH was done within 4 hours and between 18 and 24 hours, significant differences were observed between non- HIE and HIE stage 3, between HIE stage 1 and HIE stage 3 and between HIE stage 2 and HIE stage 3 with $p<0.05$. Serum LDH value was its maximum in stage $-3 \mathrm{HIE}$ at all time points, being the highest value between 18 and 24 hours.

Comparison of serum AST and ALT at different time points between the different stages of HIE is shown in Tables 3, 4 and 5. 
Table 3: Comparison of serum aspartate transaminase (AST) at different time points between the stages of hypoxic ischaemic encephalopathy (HIE)

\begin{tabular}{|c|c|c|c|c|c|c|c|c|}
\hline $\begin{array}{l}\text { AST at different time } \\
\text { points }\end{array}$ & & $\mathbf{N}$ & Mean & $\begin{array}{l}\text { Standard } \\
\text { deviation }\end{array}$ & Min & Max & F-value & p-value \\
\hline \multirow[t]{4}{*}{ Cord blood AST } & \multirow[t]{4}{*}{0} & 3 & 42.67 & 5.033 & 38 & 48 & \multirow[t]{4}{*}{1.877} & \multirow[t]{4}{*}{0.158} \\
\hline & & 10 & 52.90 & 19.046 & 28 & 96 & & \\
\hline & & 11 & 76.91 & 43.855 & 32 & 167 & & \\
\hline & & 6 & 166.83 & 218.321 & 54 & 605 & & \\
\hline \multirow[t]{4}{*}{ AST within 4 hours } & 0 & 3 & 41.00 & 3.606 & 38 & 45 & \multirow[t]{4}{*}{2.300} & \multirow{4}{*}{0.101} \\
\hline & 1 & 10 & 52.30 & 19.810 & 28 & 97 & & \\
\hline & 2 & 11 & 88.18 & 58.656 & 32 & 205 & & \\
\hline & 3 & 6 & 205.17 & 260.765 & 60 & 729 & & \\
\hline \multirow{5}{*}{$\begin{array}{l}\text { AST between } 18 \text { and } 24 \\
\text { hours }\end{array}$} & 0 & 3 & 41.00 & 3.606 & 38 & 45 & \multirow[t]{5}{*}{3.962} & \multirow[t]{5}{*}{$0.019^{*}$} \\
\hline & 1 & 10 & 51.20 & 20.253 & 28 & 100 & & \\
\hline & 2 & 11 & 90.36 & 58.848 & 32 & 205 & & \\
\hline & 3 & 6 & 302.33 & 335.202 & 62 & 737 & & \\
\hline & Total & 30 & 114.77 & 173.654 & 28 & 737 & & \\
\hline
\end{tabular}

One way ANOVA was used to compare AST values at different time points between the stages of HIE. Here we observe significant difference in
AST value between 18 and 24 hours with $\mathrm{p}<0.05$. Further, Tukey's post-hoc test was used for multiple comparisons.

Table 4: Multiple comparison of serum aspartate transaminase (AST) at different time points with the stages of hypoxic ischaemic encephalopathy (HIE)

\begin{tabular}{|l|c|c|c|c|c|}
\hline \multirow{2}{*}{ Serum AST } & (I) HIE stage & $\begin{array}{c}\text { (J) HIE } \\
\text { stage }\end{array}$ & $\begin{array}{c}\text { Mean difference } \\
\text { (I-J) }\end{array}$ & Standard error & p-value \\
\hline \multirow{3}{*}{$\begin{array}{l}\text { AST between 18 and } \\
24 \text { hours }\end{array}$} & \multirow{2}{*}{0} & 1 & -10.200 & 100.012 & 1.000 \\
\cline { 2 - 6 } & \multirow{2}{*}{1} & 2 & -49.364 & 98.958 & 0.959 \\
\cline { 2 - 6 } & & 2 & -261.333 & 107.431 & 0.096 \\
\cline { 2 - 6 } & \multirow{2}{*}{2} & 3 & -25.164 & 66.383 & 0.934 \\
\cline { 2 - 6 } & & 3 & -211.970 & 78.456 & $0.018^{*}$ \\
\hline
\end{tabular}

Tukey's post-hoc test was used for multiple comparison of serum AST values between each time points with stages of HIE. Here we observe significant differences between HIE stage 1 and
HIE stage 3 and also between HIE stage 2 and HIE stage 3 when done between 18 and 24 hours with $\mathrm{p}<0.05$

Table 5: Comparison of serum alanine transaminase (ALT) at different time points between the stages of hypoxic ischaemic encephalopathy (HIE)

\begin{tabular}{|c|c|c|c|c|c|c|c|c|}
\hline $\begin{array}{l}\text { ALT at different time } \\
\text { points }\end{array}$ & & $\mathbf{N}$ & Mean & $\begin{array}{l}\text { Standard } \\
\text { deviation }\end{array}$ & Min & Maximum & F value & $\begin{array}{l}\mathbf{P} \\
\text { value }\end{array}$ \\
\hline \multirow{5}{*}{ Cord blood ALT } & 0 & 3 & 41.67 & 2.887 & 40 & 45 & \multirow[t]{5}{*}{0.2320} & \multirow[t]{5}{*}{0.873} \\
\hline & 1 & 10 & 36.40 & 12.651 & 18 & 60 & & \\
\hline & 2 & 11 & 42.73 & 25.993 & 6 & 97 & & \\
\hline & 3 & 6 & 45.83 & 35.171 & 20 & 114 & & \\
\hline & Total & 30 & 41.13 & 22.578 & 6 & 114 & & \\
\hline \multirow{5}{*}{ ALT within 4 hours } & 0 & 3 & 42.33 & 4.509 & 38 & 47 & \multirow[t]{5}{*}{0.601} & \multirow[t]{5}{*}{0.620} \\
\hline & 1 & 10 & 35.50 & 13.242 & 18 & 58 & & \\
\hline & 2 & 11 & 43.18 & 25.980 & 6 & 97 & & \\
\hline & 3 & 6 & 58.17 & 62.506 & 18 & 184 & & \\
\hline & Total & 30 & 43.53 & 32.0077 & 6 & 184 & & \\
\hline \multirow{5}{*}{$\begin{array}{l}\text { ALT between } 18 \text { and } \\
24 \text { hours }\end{array}$} & 0 & 3 & 42.00 & 4.000 & 38 & 46 & \multirow[t]{5}{*}{1.587} & \multirow[t]{5}{*}{0.217} \\
\hline & 1 & 10 & 35.30 & 13.200 & 19 & 58 & & \\
\hline & 2 & 11 & 44.55 & 24.197 & 8 & 97 & & \\
\hline & 3 & 6 & 75.50 & 74.010 & 16 & 184 & & \\
\hline & Total & 30 & 47.40 & 37.702 & 8 & 184 & & \\
\hline
\end{tabular}


Paired t-test was used to compare ALT values between different time points. Here we observe no significant difference in ALT values when different time points were compared to each other among HIE neonates. Serum AST showed highest elevation between 18 and 24 hours.
Correlation of LDH, AST and ALT between the stages of HIE at different time points is shown in Table 6.

Table 6: Correlation of dehydrogenase (LDH), aspartate transaminase (AST) and alanine transaminase (ALT) between the stages of hypoxic ischaemic encephalopathy (HIE) at different time points

\begin{tabular}{|c|c|c|}
\hline & & HIE stage \\
\hline \multirow[t]{3}{*}{ Cord blood LDH } & Correlation Coefficient & $0.674 * *$ \\
\hline & SIG.(2-TAILED) & .000 \\
\hline & $\mathrm{N}$ & 30 \\
\hline \multirow[t]{3}{*}{ Cord blood AST } & Correlation Coefficient & $0.446^{*}$ \\
\hline & SIG.(2-TAILED) & 0.013 \\
\hline & $\mathrm{N}$ & 30 \\
\hline \multirow[t]{3}{*}{ Cord blood ALT } & Correlation Coefficient & -.033 \\
\hline & SIG.(2-TAILED) & .861 \\
\hline & $\mathrm{N}$ & 30 \\
\hline \multirow[t]{3}{*}{ LDH within 4 hours } & Correlation Coefficient & $0.526 * *$ \\
\hline & SIG.(2-TAILED) & .000 \\
\hline & $\mathrm{N}$ & 30 \\
\hline \multirow[t]{3}{*}{ AST within 4 hours } & Correlation Coefficient & $0.526 * *$ \\
\hline & SIG.(2-TAILED) & .003 \\
\hline & $\mathrm{N}$ & 30 \\
\hline \multirow[t]{3}{*}{ ALT within 4 hours } & Correlation Coefficient & 0.002 \\
\hline & SIG.(2-TAILED) & .992 \\
\hline & $\mathrm{N}$ & 30 \\
\hline \multirow[t]{3}{*}{ LDH between 18 and 24 hours } & Correlation Coefficient & $0.745 * *$ \\
\hline & SIG.(2-TAILED) & .000 \\
\hline & $\mathrm{N}$ & 30 \\
\hline \multirow[t]{3}{*}{ AST between 18 and 24 hours } & Correlation Coefficient & $0.549 * *$ \\
\hline & SIG.(2-TAILED) & 0.002 \\
\hline & $\mathrm{N}$ & 30 \\
\hline \multirow[t]{3}{*}{ ALT between 18 and 24 hours } & Correlation Coefficient & 0.055 \\
\hline & SIG.(2-TAILED) & 0.773 \\
\hline & $\mathrm{N}$ & 30 \\
\hline
\end{tabular}

All the 6 babies who had expired ( 6 babies), (HIEstage 3), had a very high level of LDH at all 3 time points with the maximum mean value of 4989 units per dl at 24 hours. Similarity AST was found elevated with significant $p$ value $(0.038)$ in terms of outcome among HIE babies whereas ALT was not found to be significant.

\section{Discussion}

In our study we assessed the levels of serum LDH, AST and ALT among asphyxiated term neonates at frequent intervals in the first 24 hours of birth. In our study, $53.3 \%$ of asphyxiated babies were males and $46.7 \%$ were females and this is in accordance with the several other studies which noted male gender preponderance ${ }^{6,7,8}$. In our study, majority of the asphyxiated babies were appropriate for gestational age. Babies with birth weights between $2.6 \mathrm{~kg}$ to $3.5 \mathrm{~kg}$ and gestational age between 37 to 39 weeks were found less risky than above 39 completed weeks which is similar to the study done by Badawi et al ${ }^{9}$.

In our study, $43.3 \%$ of asphyxiated babies were born to primigravida mothers and the mean age of mother was 22 years similar to the study done by Bashir et $a l^{10}$. The major risk factors for birth asphyxia were meconium stained liquor (43.3\%) 
followed by prolonged second stage (26.7\%) but our study did not contribute any major observation regarding $\mathrm{PIH}$ which is similar to other studies whereas preeclampsia/eclampsia was more significantly associated with birth asphyxia ${ }^{11,12}$. According to Boskabadi et $a l^{13}, 40.4 \%$ of asphyxiated babies with abnormal outcome were born through normal delivery and $59.6 \%$ born through emergency lower segment caesarean section (LSCS). Similarly, in our study, $83.3 \%$ of stage 3 were born through emergency LSCS. In our study, among the total asphyxiated babies, kidney involvement was seen more frequently $(16.7 \%)$. In the study done by Dan et al, AKI was seen in $11.7 \%$ and they observed that there was almost a 15-fold increased risk of developing AKI in $\mathrm{HIE}^{14}$.

In our study, when LDH values at different time points between the stages of HIE were compared, we observed a rising trend in serum LDH value at different time points as the severity of HIE increased at each time point. Maximum serum LDH value was observed when done in HIE stage 3 between 18 to 24 hours (mean LDH-4989.00 +2717.940 ). According to the study done by Choudhary et $a l^{15}$, though there was a statistical difference in the LDH levels between asphyxiated and non-asphyxiated babies, difference was more significantly observed on day 3 with the rising trend observed in the advanced HIE staging and also among various HIE stages, the difference in LDH was statistically significant between HIE 0-II $(p<0.001)$, HIE 0 -III $(p<0.001)$, HIE I-II $(p<0.001)$, and HIE I-III $(p<0.001)$, while it was statistically insignificant when compared between HIE $0-$ I and HIE II- III $(p>0.05)$.

In our study, when serum LDH was done within 4 hours and between 18 and 24 hours, significant differences were observed between HIE 0-3, between HIE stage-1-3 and between HIE stage 2-3 $(p<0.05)$. Some recent studies have been done on salivary LDH levels too and found to be increased compared to the control groups. (1379-3408 IU per litre $)^{16}$. In a study done by Reddy $\mathrm{S}$ et al $^{17}$, it was noted that LDH had $100 \%$ sensitivity when done at 72 hours of life with maximum area under ROC curve but in our study, it is also noted that as early as cord blood can show elevated levels of LDH in asphyxiated babies. Thoresen et al, further studied LDH levels as a potential biomarker as to predict the outcome in hypothermiated (therapeutic) babies and found that LDH more than 2085U/L had an adverse outcome ${ }^{18}$.

According to Kabbany et al, the highest increase in AST and ALT in relation to baseline was observed at 49 to 72 hours of life (mean AST $=160 \pm 81$ $\mathrm{U} / \mathrm{L})$ (mean $\mathrm{ALT}=146 \pm 75 \mathrm{U} / \mathrm{L}$ ) which then decreased below the baseline at 6 to 12 days
$(69.8+20 \mathrm{U} / \mathrm{L})^{18}$. Since we did not follow it up after 24 hours we have not seen the significant rise in ALT levels. Since AST is present in other tissues other than the liver that may be the reason for more increase in AST compared to ALT which will be raised only in liver injury. According to Chavvi et $a l,{ }^{5}$ in their prospective study, $56 \%$ developed birth asphyxia with liver injury (ALT $>81 \mathrm{U} / \mathrm{L})$. Compared to normal controls, asphyxiated babies had higher levels of ALT, AST, and LDH which peaked at 24-72 hours. Decrease in these enzyme levels were observed by 6 to 12 days. There was no correlation between the liver enzymes levels and severity of HIE which is in contrast to our study where we found a strong correlation with the increasing severity, but we got lower mean levels of AST (97U/L) and ALT (43U/L) within 24 hours compared to their study.

A significant $p$ value of 0.02 has been observed when cord blood LDH values were compared between expired and alive groups of asphyxiated babies. There was a significant difference observed when serum AST was done within 4 hours and between 18 to 24 hours among asphyxiated neonates in terms of their outcome. According to Awaysheh et $a l^{19}$, serum CPK and serum LDH were measured among asphyxiated neonates in the initial 2 hours of life and it was found that serum LDH (mean value $1473 \pm 688$ ) and CPK (mean value $1562 \pm 881$ ) were significantly higher among them and had a good outcome as they initiated therapeutic hypothermia within 6 hours. In HIE stage 3, serum LDH value in cord blood showed a 5 fold increase from the normal LDH value of a non-asphyxiated neonate, 7.5 fold increase in HIE stage 3 when done within 4 hours and as high as 11 fold increase from the normal LDH value when done between 18 to 24 hours. This shows that serum LDH is the best biomarker and it increases according to the severity of HIE from cord blood to 24 hours of life in an asphyxiated neonate compared to AST which showed maximum elevation of 2.1 fold and ALT 1.5 fold.

The results of our study will be useful for the paediatricians to decide the management especially therapeutic hypothermia which has to be initiated within 6 hours of life and to categorize the babies according to the severity when they receive asphyxiated neonates with unreliable birth history, records and prior treatment. In such conditions, the importance of serum LDH and serum AST would come into the scenario as biomarkers of asphyxia and HIE. Further studies should be done to find out the specificity and sensitivity of serum LDH in terms of outcome in HIE neonates

\section{Conclusions}

This study concluded that the best time period for 
predicting severity of asphyxia in terms of serum LDH is between 18 to 24 hours whereas high cord blood LDH value would suggest increased severity of asphyxia. The best time period in terms of serum AST is between 18 to 24 hours in terms of severity of asphyxia, whereas serum ALT does not show any significance at any point of time within 24 hours.

\section{References}

1. Lozano R, Naghavi M, Foreman K, Lim S, Shibuya K, Aboyans V et al. Global and regional mortality from 235 causes of death for 20 age groups in 1990 and 2010: a systematic analysis for the Global Burden of Disease Study 2010. Lancet 2012; 380(9859): 2095-128. https://doi.org/10.1016/S01406736(12)617 28-0

2. Agarwal R, Jain A, Deorari AK, Paul VK. Post resuscitation management of asphyxiated neonates. Indian Journal of Pediatrics 2008; 75(2): 175-80. https://doi.org/10.1007/s12098-008-00265

3. National Neonatal Perinatal Database. Report for the year 2002-03. Available at: http://www.newbornwhocc.org/pdf/nnpd report_2002-03.PDF (accessed on 14th August 2018).

4. Hansen AR, Soul JS. Perinatal asphyxia and hypoxic ischaemic encephalopathy. In: Eichenwald EC, Hansen AR, Martin CR, Stark AR, editors. Cloherty and Stark's manual of neonatal care, $8^{\text {th }}$ South Asian ed. New Delhi: Wolters Kluwer; 2017.p. 790-811.

5. Thoresen M, Liu X, Jary S, Brown E, Sabir H, Stone J et al. Lactate dehydrogenase in hypothermia-treated newborn infants with hypoxic-ischaemic encephalopathy. Acta Pcediatrica 2012; 101:1038-44.

https://doi.org/10.1111/j.16512227.2012.0 2778.x

6. Chhavi N, Zutshi K, Singh NK, Awasthi A, Goel A. Serum liver enzyme pattern in birth asphyxia associated liver injury. Pediatric Gastroenterology, Hepatology and Nutrition 2014; 17(3):162-9. https://doi.org/10.5223/pghn.2014.17.3.16 2
7. Boskabadi H, Ashrafzadeh F, Doosti H, Zakerihamidi M. Assessment of risk factors and prognosis in asphyxiated infants. Iranian Journal of Pediatrics 2015; 25(4):1-5. https://doi.org/10.5812/ijp.2006

8. Butt TK, Farooqui R, Khan MAU. Risk factors for hypoxic ischaemic encephalopathy in children, Journal of the College of Physicians and Surgeons Pakistan 2008; 18(7): 428-32.

9. Badawi N, Kurinczuk JJ, Keogh JM, Alessandri LM, O'Sullivan F, Burton PR, et al. Antepartum risk factors for newborn encephalopathy: The Western Australian case-control study. British Medical Journal 1998; 317:1549-53. https://doi.org/10.1136/bmj.317.7172.154 9

10. Itoo BA, Al-Hawsawi ZM, Khan AH, Hypoxic ischaemic encephalopathy: Incidence and risk factors in North Western Saudi Arabia. Neurosciences 2003; 8(2):113-9.

11. Aslam HM, Saleem S, Afzal R, Iqbal U, Saleem SM, Shaikh MWA et al. Risk factors of birth asphyxia. Italian Journal of Pediatrics 2014; 40:94. https://doi.org/10.1186/s13052-014-00942

12. Chiabi A, Nguefack S, Evelyne MAH, Nodem S, Mbuagbaw L, Mbonda E, et al. Risk factors for birth asphyxia in an urban health facility in Cameroon. Iranian Journal of Child Neurology 2013; 7(3): 46-54.

13. Boskabadi H, Ashrafzadeh F, Doosti H, Zakerihamidi M. Assessment of risk factors and prognosis in asphyxiated infants. Iranian Journal of Pediatrics 2015; 25(4): e2006. https://doi.org/10.5812/ijp.2006

14. Alaro D, Bashir A., Musoke R. Prevalence and outcomes of acute kidney injury in term neonates with perinatal asphyxia. African Health Sciences 2014; 14:682-8.

https://doi.org/10.4314/ahs.v14i3.26

15. Choudhary M, Sharma D, Dabi D, Lamba M, Pandita A, Shastri S. Hepatic dysfunction in asphyxiated neonates: 
Prospective case-controlled study. Clinical Medicine Insights: Pediatrics 2015; 9:1-6. https://doi.org/10.4137/CMPed.S21426

16. Mehta A, Chawla D, Kaur J, Mahajan V, Guglani V. Salivary lactate dehydrogenase levels can provide early diagnosis of hypoxic-ischaemic encephalopathy in neonates with birth asphyxia. Acta Paediatrica 2015; 104(6): e236-40. https://doi.org/10.1111/apa.12964

17. Reddy S, Dutta S, Narang A. Evaluation of lactate dehydrogenase, creatine kinase and hepatic enzymes for the retrospective diagnosis of perinatal asphyxia among sick neonates. Indian Pediatrics 2008; 45(2):144-7.
18. El- Kabbany ZA, Hamza RT, Toaima NN. Early hepatic dysfunction in asphyxiated full term newborns. SM Liver Journal 2017; 2(1): 1006.

19. Awaysheh F, Bsharat A, Alhmaiedeen N, Al-Ghananim R, Al-hassan M. Early biochemical markers of hypoxic ischaemic encephalopathy in neonates. Journal of the Royal Medical Services 2016; 23 (4):2016.

https://doi.org/10.12816/0032194 